\title{
Por uma semiótica do mal: "The imp of the perverse”, de Edgar Allan Poe
}

Leonardo Vieira de Almeida ${ }^{1}$

Resumo: Publicado pela primeira vez no Graham's Lady's and Gentleman's Magazine, em julho de 1845, o conto "The imp of the perverse", de Edgar Allan Poe, trata de um insólito acontecimento: o assassinato premeditado por intermédio de um ato de leitura. Procurando desvendar a causa secreta da impulsividade humana, Poe questiona a acepção da liberdade, já que o homem é livre na medida em que o gesto do pensamento pode ser sua perdição. Ou seja, se o narrador em primeira pessoa infringe a lei, buscando a liberdade, consegue esta na sua própria impossibilidade: é livre para perder o direito de sê-lo. Desse modo, o paradoxo do autor de $O$ corvo se constrói mediante a proliferação do "gênio maligno", de René Descartes, descrito em suas Meditações, a qual se afirma por uma semiótica do mal, procedimento que tem na anatomia do impulso seu móbil particular.

Palavras-chave: Semiótica do mal. Paródia. Metaconto. Teoria da impulsividade.

No conto "The imp of the perverse", publicado pela primeira vez no Graham's Lady's and Gentleman's Magazine, em julho de 1845, Edgar Allan Poe apresenta a história de um homem cuja queda irrevogável se dá por meio do que ele nomeia perversidade. Como tantos outros narradores em primeira pessoa do autor norte-americano, este personagem não revela seu nome. Sabe-se, no início do relato, que ele é inimigo acirrado da frenologia, a qual, segundo sua opinião, é uma ciência planejada a priori.

De fato, esta ciência, concebida pelo médico austríaco Franz Joseph Gall, em 1796, constituiu-se como a primeira teoria completa de localizacionismo cerebral, cujo fundamento considerava as faculdades morais e intelectuais do homem como inatas. Sua manifestação dependeria da organização do cérebro, que o cientista austríaco julgava ser o responsável por todas as inclinações, sentimentos e faculdades. Assim, a frenologia seria a doutrina segundo a qual cada faculdade da mente se localizaria em uma parte do córtex cerebral e o tamanho de cada uma de suas partes diretamente proporcional ao desenvolvimento da faculdade correspondente, sendo este tamanho indicado pela configuração externa do crânio. Gall realizou inúmeras observações e executou muitas medidas experimentais em crânios de seus

\footnotetext{
${ }^{1}$ Leonardo Vieira de Almeida é escritor, doutor em Letras, professor substituto de Literatura da Faculdade de Formação de Professores da UERJ e pesquisador da Cátedra Unesco de Leitura, na PUC-Rio. Autor dos livros de contos Os que estão aí (Ibis Libris, 2002); A flor no rosto (Multifoco, 2010) e Veredas do grande conto: a descoberta do sertão em Guimarães Rosa (ensaio), pela editora da PUC-Rio em coedição com a Uapê, em 2011 (Prêmio Antonio Olinto, da União Brasileira de Escritores, 2012). E-mail: leonardo38vieira@ gmail.com.
} 
parentes, amigos e estudantes, de modo a conseguir relacionar determinadas faculdades mentais a elevações e depressões na superfície do crânio, desenvolvendo mapas topológicos detalhados. O colaborador mais importante de Franz Joseph Gall foi Johann Spurzheim, que, posteriormente, o auxiliaria a tornar mais desenvolvido o modelo frenológico e divulgá-lo na Europa e nos Estados Unidos.

Em “The imp of the perverse", a crítica à frenologia e às ciências ditas metafísicas se pauta em estabelecer um ataque ao homem intelectual ou lógico, responsável, na opinião do narrador, por imaginar projetos e ditar objetivos a Deus. Para demonstrar este argumento, mostra que os ditames impostos pela divindade são desígnios a priori que devem reger os processos humanos. Desta forma, se faz parte da vontade de Deus que o homem coma, então se atribui a este último um órgão de alimentação, que passa a ser o móbil que impele a natureza humana a comer, quer queira, quer não. Por conseguinte, haveria órgãos que representariam uma propensão, um sentimento moral ou uma faculdade do intelecto puro, como aqueles da amatividade, combatividade, idealidade, casualidade, construtividade. Após enumerar esta série de atributos, o personagem chega a afirmar que seria mais seguro investigar o homem por si mesmo do que supor Deus como o responsável pelos atos humanos. Para tanto, se não se pode compreender Deus nas suas obras visíveis, como seria possível entendê-lo nos inconcebíveis pensamentos que dão vida às suas obras? E, além disso, se não se pode apreender a divindade nas suas criaturas objetivas, como seria possível percebê-la nas suas disposições de ânimo substantivas e nas suas fases de criação?

Dividido em duas partes, um ensaio e um conto propriamente dito, o texto de Edgar Allan Poe tem como leitmotiv o descrédito em uma causa que possa explicar os impulsos humanos. Em contrapartida a uma indução $a$ priori, o personagem propõe que uma indução $a$ posteriori teria levado à derrocada da ciência frenológica, já que algo de paradoxal, a perversidade, deveria ser admitido como um princípio inato e primitivo da ação do homem. Sob a influência desse "mobile sem motivo", se age sem um objetivo compreensível, ou melhor dizendo, se age pelo motivo de que não se deve agir. Para corroborar esta hipótese, o narrador chega a considerar:

I am not more certain that I breathe, than that the assurance of the wrong or error of any action is often the one unconquerable force which impels us, and alone impels us to its prosecution. Nor will this overwhelming tendency to do wrong for the wrong's sake, admit of analysis, or resolution into ulterior elements. It is a radical, a primitive impulse - elementary. It will 
be said, I am aware, that when we persist in acts because we feel we should not persist in them, our conduct is but a modification of that which ordinarily springs from the combativeness of phrenology ${ }^{2}$ (POE, 1946, p. 362-363). (Grifo meu).

A alusão ao engano ou erro como condicionante do impulso leva a inferir que, de fato, seriam o logro e a ilusão agentes que sustentam o mundo, se este for um composto de sonho e realidade, sem que estas instâncias possam estar claramente delimitadas. Mais adiante, darse-á atenção ao fato de que a perversidade é uma direta instigação do demônio, o qual, por exemplo, faz com que um homem, à borda de um precipício, por mais que trema e não queira se lançar no abismo, é atraído, por fim, para a própria destruição. Na segunda parte do conto, o personagem relata como cometeu o assassinato deliberado de um leitor. Pesquisando algumas memórias francesas, ele encontra a narrativa de uma doença fatal que quase levou à morte uma senhora em decorrência de uma vela acidentalmente envenenada. Servindo-se da mesma estratégia, provoca em sua vítima, um homem que tinha o hábito de ler na cama, a morte por envenenamento.

A questão da leitura como um ato letal e o demônio como aquele que semeia a ilusão no mundo são linhas de abordagem delineadas por René Descartes, particularmente em seu livro Meditações, publicado em 1641. Nesta obra, o filósofo francês, sustentando que, se Deus é o sumo bem e, portanto, seria incompatível com sua índole permitir que o homem se enganasse sempre, propõe, em lugar do verdadeiro Deus, um gênio maligno, astucioso e poderoso, que dedicou todo o seu empenho em enganar a humanidade. Assim, Descartes alude ao ponto de que o céu, ar, terra, cores, figuras, sons e todas as coisas exteriores visíveis não seriam mais do que ilusões e fraudes das quais esse gênio maligno se serve para rasurar a credulidade. De fato, tal prognose poderia ser encarada como um desenvolvimento de hipóteses apontadas na obra de 1637, O discurso do método, em que o pensamento cartesiano parte da dúvida mediante a máxima "Duvido, logo penso", para, por um processo de gradação racional, suprimir o ceticismo do mundo por meio da expressão "Penso, logo existo". Nesse

\footnotetext{
${ }^{2} \mathrm{Na}$ tradução de Oscar Mendes: "Tenho menos certeza de que respiro do que a de ser muitas vezes o engano ou o erro de qualquer ação a força inconquistável que nos empurra, e a única que nos impele a continuá-lo. E não admitirá análise ou resolução em elementos ulteriores esta acabrunhante tendência de praticar o mal pelo mal. É um impulso radical, primitivo, elementar. Dir-se-á, estou certo que, quando nós persistirmos em atos porque sentimos que não deveríamos persistir neles, nossa conduta é apenas uma modificação daquela que ordinariamente se origina da combatividade da frenologia" (POE, 1981, p. 206-207). Apesar de tomar como referência para as citações do conto de Edgar Allan Poe a tradução de Oscar Mendes, "O demônio da perversidade", não é irrelevante desconsiderar a falha do tradutor, em que a estratégia poeana com a palavra imp
} 
sentido, a princípio, o pensar, para Descartes, seria uma salvação, possibilidade de se erradicar o gênio maligno por intermédio do Deus veraz, o Deus Razão, das matemáticas, de modo que é nas ciências que se deve encontrar algo de imutável e indubitável. No entanto, permanece, como veículo da quimera, a própria linguagem, agenciadora do fingimento em um teatro da ilusão, pois, como ratifica o autor de Das paixões da alma:

Porque, ainda que sem falar eu considere tudo isso em mim mesmo, as palavras me contêm e sou quase enganado pelos termos da linguagem comum; porque, se a mostram a nós, dizemos que estamos vendo a mesma cera, e não que julgamos tratar-se da mesma, pelo fato de apresentar a mesma cor e a mesma aparência: de onde desejaria quase concluir que se conhece a cera pela visão e não apenas pela análise do espírito, se por acaso não divisasse pela janela pessoas que passam pela rua, à vista das quais afirmo que vejo pessoas do mesmo modo que afirmo que vejo a cera; e, contudo, o que avisto pela janela, a não ser chapéus e casacos que podem cobrir figuras ou pessoas fictícias que se movem por meio de molas? (DESCARTES, 2000, p. 266).

Ao conceber, nesta passagem, uma percepção da realidade como uma instância do fictício, Descartes parece querer construir para a filosofia uma residência que a aproxima da literatura. Ainda em $O$ discurso do método, o filósofo propõe que a obra a qual está escrevendo não passa de uma história, ou, como ele diz, de uma fábula. E, retomando suas Meditações, submete à apreciação a ideia de que uma pessoa que busca ampliar seu conhecimento deve ultrapassar o ordinário. Dessa forma, permite-se apreender que dois motivos sustentados e criticados pela filosofia do pensador francês, a realidade como fábula e o ordinário como terreno do ceticismo, serão retomados pelo contista Edgar Allan Poe na América de meados do século XIX. No caso de "The imp of the perverse", o próprio título já apresenta esta confluência, pois imp pode ser tanto uma pequena criatura de história de fadas, que tem poderes mágicos e frequentemente causa problema de um modo brincalhão, quanto uma criança do demônio, diabrete, criança travessa e brincalhona. Além disso, há de se atentar para o fato de que imp- é um prefixo, disseminado no início de várias palavras do conto de Poe, tais como: impulso (impulse), impelir (impel), importante (important), impertinente (impertinent), imperceptível (imperceptible), impossível (impossible), impetuosamente (impetuously), não impressionante (unimpressive).

A esse respeito, diz o filósofo norte-americano Stanley Cavell, em seu ensaio "Being

é elidida. Assim, creio que o melhor título em português para esta peça curta seria "O ímpio". 


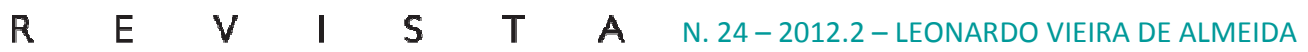

odd, getting even (Descartes, Emerson, Poe)", o qual integra o livro In the quest of ordinary: lines of skepticism and romanticism, que, em inglês, imp. é uma abreviatura de imperativo, imperfeito, imperial, imprimátur, impessoal, implemento, impróprio e melhoria (improvement). Ou seja, no âmbito semiótico, falar do diabrete da perversidade no conto de Edgar Allan Poe, segundo Cavell, seria nomear o diabrete em inglês, o que remete a falar da própria linguagem, em particular do ramo anglo-saxão, como perversa.

Esta perversidade das palavras, a qual corresponde, no campo semiótico, ao âmbito semântico, foi a semente que, na América inglesa, permitiu à literatura encampar o gesto filosófico mediante uma semiose do mal.

No caso de outro conto de Poe, "O gato preto", publicado quase dois anos antes de “The imp of the perverse", no United Saturday Post, em 1843, observa-se a história de um outro personagem também não nomeado e que fora dócil e humano de caráter, com extrema dedicação e afeição aos animais. Depois de casado com uma mulher de índole afim, o narrador revela seu especial interesse por Plutão, um gato preto pelo qual nutre profunda amizade. No entanto, sem razão aparente, a esta criatura tão amada é infligido o suplício de ter um dos olhos extraídos com um canivete e, algum tempo depois, ela é enforcada com um laço num ramo de árvore. Tentando devassar os desígnios do "espírito da perversidade", o assassino diz que deste "não cuida a filosofia". De modo a delinear alguns traços do argumento, considera a perversidade "um dos impulsos primitivos do coração humano, uma das indivisíveis faculdades primárias, ou sentimentos, que dão direção ao caráter do homem" (POE, 1981, p. 144). Tempos depois do assassinato do animal de estimação, surge outro gato, idêntico ao primeiro, inclusive faltando-lhe um olho, só que com a diferença de possuir a mancha branca de uma forca em seu peito. A antipatia por este novo animal também começa a crescer desenfreadamente, até que o homem, num ataque de cólera, tenta matá-lo com um machado. Por infortúnio, a esposa do personagem intervém e é morta por um golpe da arma branca no crânio. A saída para o marido é emparedá-la em uma adega e, após três dias de realizado tal ato, sente-se livre. Agentes de polícia vêm investigar o local e nada encontram de suspeito. Quando se acham prontos para partir, o júbilo de satisfação no coração do homem é tão grande que ele começa a contar sobre a excelente solidez das paredes da casa, por sinal, muito bem construídas, e bate com uma bengala naquela parte da construção sob a qual a mulher fora escondida. Como resposta, a repercussão das pancadas ecoa em um gemido de criança que se transforma num guincho inumano que se ergue "das gargantas dos danados na 


\section{$\begin{array}{llllllll}\mathbf{R} & \mathbf{E} & \mathbf{V} & \mathbf{I} & \mathbf{S} & \mathbf{T} & \mathbf{A} & \text { N. 24-2012.2-LEONARDO VIEIRA DE ALMEIDA }\end{array}$}

sua agonia e dos demônios que exultam na danação" (POE, 1981, p. 151). Os agentes desmancham a parede e se revela em seu interior o cadáver decomposto e manchado de coágulos da mulher, com o gato preto, sobre sua cabeça, delatando o crime.

A premissa do conto, tal qual em "The imp of the perverse", é recorrente nas formas breves do escritor estadunidense, e deixa à mostra, na dissecação de sua anatomia, os órgãos vitais. Os mecanismos da perversidade, impulso, emparedamento, eco, liberdade são aqueles responsáveis pelo que não cuida a filosofia, segundo o "filósofo" Poe. É possível referir que o escritor de $O$ corvo é o descendente direto de um modo de pensamento até então ausente na América. Este modo de pensamento estaria ligado a uma anatomia ou teoria de impulsividade, que é a filosofia dirimida na forma breve, o conto. De fato, foi esta forma a responsável por estabelecer a topologia sobre a qual a perversidade poderia ser encarada como suscitadora do pensamento, no que este se desliga de uma anatomia racionalista. A alusão à "Lição de anatomia do Doutor Nicolaes Tulp", de 1632, de Rembrandt, não é de menos importância, caso se aponte que o cirurgião representado, enquanto secciona o músculo e os tendões que servem para mover os dedos do cadáver, segue a comparação feita por Aristóteles de que os dedos da mão são os correspondentes físicos da razão e da inteligência humanas, como comprova a origem da palavra grega cirurgião, aquele responsável por gestos absolutamente precisos, já que kheirourgía quer dizer "ação de trabalhar com a mão". No entanto, para certos personagens de Poe, este membro do corpo humano é o que foge ao atributo racionalista. Assim, no caso do homem que assassina o gato, a esposa e delata o crime. Do mesmo modo, no conto publicado poucos meses antes de "O gato preto", "O coração denunciador", no qual o morador de uma pensão, obcecado pelo olho de abutre e as batidas do coração de um velho, chega a matá-lo, desmembrá-lo e ocultá-lo sob as pranchas do assoalho. A polícia, alertada por um alarme noturno, chega à pensão, mas nada encontra de aparentemente suspeito. No entanto, quando os policiais estão prestes a partir, o personagem, invadido pelo som grave, monótono, rápido, “muito semelhante ao de um relógio envolto em algodão" (POE, 1981, p. 140) que, segundo ele, reverbera no coração do assassinado, retira as pranchas do chão e revela seu crime.

Assim, a hipótese de uma teoria da impulsividade, no caso de Edgar Allan Poe, vem contra a supressão do malin génie cartesiano, o que possibilitaria encontrar no paradoxo uma morada que, no exemplo da América, eliminaria a distância entre filosofia e literatura pela reiteração do mal. Mal este que, sob o influxo do puritanismo, encontrou nos sermões do 
pastor Cotton Mather, no século XVII, a fórmula acusadora que atingiria no julgamento de Salem a sua mais alta forma de barbárie, em que dezenove inocentes foram condenados à morte por suspeita de possessão demoníaca. Condenação esta que seria retomada pelo escritor Nathaniel Hawthorne, contemporâneo de Poe, quem, na letra escarlate cardada no lado esquerdo das vestes de Hester Prynne, amante de Arthur Dimmesdale, sobre seu coração, signo tanto do adultério quanto do angelismo, no romance The scarlet letter, de 1850, seria um pálido esforço de fatura concretista a qual tomaria, no caso da tale norte-americana, um estatuto singular. Ou seja, a letra "A", inicial de adulteress e angel ${ }^{3}$, imposta a Hester como estigma de condenação do pecado em uma sociedade puritana na Nova Inglaterra do século XVII, caracteriza um índice de iconização do verbal, estratégia semiótica que, no caso de Edgar Allan Poe, atinge um alto grau de problematização.

Deste modo, numa época de ascensão dos periódicos, do jornal e da revista, corre em paralelo, na literatura poeana, uma exploração das possibilidades tipográficas, a ponto de em “A balela do balão", publicado em abril de 1844 no New York Sun, Poe forjar uma das páginas do conto como uma folha de jornal, atendo-se a inscrever caracteres de tipografia sobre a superfície em branco ${ }^{4}$. E se se toma como baliza para o conto do autor de "A queda da casa de Usher" uma "teoria da impulsividade" (que não se desliga dos aspectos de concreção da linguagem), é importante ter em vista que Hawthorne, em 1835, ou seja, dez anos antes de "The imp of the perverse", concebe "Wakefield", história que integra o livro de contos Twicetold tales, publicado em dois volumes em 1842, em Boston, por James Munroe and Company.

Neste relato, o narrador em primeira pessoa, que parte da leitura de uma notícia publicada em jornal londrino, relata como um homem, tomado pelo desejo de ser o voyeur da própria esposa, decide afastar-se de casa por apenas um dia, ocupando residência próxima ao seu lar. Este impulso sem razão extrapola qualquer medida plausível de tempo, pois o Sr. Wakefield, excitado por sua atitude, termina por gastar vinte anos da existência apartado da esposa. Hawthorne enfatiza um dado curioso, um "sorriso velhaco", que transparece nos

\footnotetext{
${ }^{3}$ Faz-se importante assinalar que Hester, esposa do médico Roger Chillingworth, ascende da condição de ultrajada pelo crime de adultério ao de arcana, conselheira das mulheres da comunidade em que vive. Outro ponto importante a se aludir é que a filha da heroína, fruto de sua relação com Dimmesdale, chama-se Pearl, pérola, a qual, nascida de um intercurso pecaminoso, estaria ligada simbolicamente à perfeição angélica. Pearl também é a criança-elfo, espírito que se constitui, segundo a acepção de Chevalier e Gheerbrant, como uma emanação confusa das paixões nascentes e dos primeiros sonhos de amor, símbolo das forças inconscientes do desejo, dos impulsos. Cf. Jean Chevalier; Alain Gheerbrant (1995, p. 363-364).
} 
lábios do personagem, desde o momento em que iniciou sua aventura até o instante em que decide retornar a casa, no vigésimo ano de seu desaparecimento, numa noite tempestuosa de outono. Após descrever a entrada de Wakefield pela porta do antigo lar, o narrador apõe uma nota ao final do conto ${ }^{5}$, de certo modo buscando compreender o rastro de impulsividade que levou o personagem a perpetrar o insólito plano:

This happy event - supposing it to be such - could only have ocurred at an unpremeditated moment. We will not follow our friend across the threshold. He has left us much food for thought, a portion of which shall lend its wisdom to a moral, and be shaped into a figure. Amid the seeming confusion of our mysterious world, individuals are so nicely adjusted to a system, and systems to one another, and to a whole, that, by stepping aside for a moment, a man exposes himself to a fearful risk of losing his place forever. Like Wakefield, he may become, as it were, the Outcast of the Universe (HAWTHORNE, s/d, p. 202). ${ }^{6}$

Desse modo, se o narrador do conto de Hawthorne procura, inutilmente, o móbil das ações de Wakefield, o que leva à falência em se apreender as razões de seus impulsos, por seu turno, em "The imp of the perverse", de Edgar Allan Poe, o artífice do mal, que engendra a morte de um homem por um ato de leitura, chega a dizer que "pensar era estar perdido". De fato, nas linhas do romantismo de Poe opera-se uma distorção paródica do Cogito, ergo sum de René Descartes, já que o ordinário, enquanto condição proliferante do gênio maligno das palavras, estatui-se como a condição irônica sobre o imprimátur - palavra de etimologia latina que significa imprima-se, e com a qual os censores régios ou eclesiásticos exprimiam a

\footnotetext{
${ }^{4} \mathrm{O}$ conto "The balloon-hoax" é concebido como um artigo jornalístico que relata a travessia de setenta e cinco horas empreendida pela máquina voadora do Sr. Monck Mason através do Oceano Atlântico, da Europa aos Estados Unidos, fato que nunca chegou a ocorrer.

${ }^{5}$ No que diz respeito a este ponto, vale a pena ter em vista a opinião de Edgar Allan Poe, exposta na segunda de suas três resenhas sobre Twice-told tales, publicadas entre 1842 e 1847, sendo as duas primeiras no Graham's Magazine e a última, no Godey's Lady's Book: "Seria bastante difícil designar qual o melhor conto do conjunto. Repetimos que, sem nenhuma exceção, são belos. 'Wakefield' é extraordinário, pela habilidade com que uma ideia antiga - um incidente bem conhecido - é elaborada ou discutida. Um homem cheio de caprichos propõe-se a abandonar a esposa e a morar incógnito, por vinte anos, nas imediações de sua própria casa. Um incidente deste tipo de fato ocorreu em Londres. A força do conto do Sr. Hawthorne está na análise dos motivos que devem ou podem ter impelido o marido à tamanha loucura, em primeiro lugar. E com as possíveis causas de sua persistência, em segundo. Sobre esta tese um quadro de singular força foi construído".

${ }^{6} \mathrm{Na}$ tradução de Zaida Maldonado: "Este acontecimento feliz — mesmo supondo-se que o seja — só poderia ter ocorrido em um momento impensado. Não seguiremos nosso amigo além da soleira. Ele nos deixou bastante no que pensar, uma parte do que prestará sua sabedoria a uma moral, e se moldará em uma figura. Entre a aparente confusão de nosso misterioso mundo, os indivíduos se ajustam tão bem a um sistema, e os sistemas uns aos outros e ao todo, que, ao pisar de lado por um momento, um homem se expõe ao temível risco de perder seu lugar para sempre. Como Wakefield, ele pode se tornar, por assim dizer, um Pária do Universo." Cf. http://www.bestiario.com.br/5_arquivos/Wakefield.html.
} 
autorização para qualquer obra ser impressa -, cuja abreviatura é imp. Ainda no dizer de Stanley Cavell:

[...] if to speak of the imp of the perverse is to name the imp in English, namely as the initial sounds of a number of characteristically Poe-ish terms, then to speak of something called the perverse as containing this imp is to speak of language itself, specifically of English, as the perverse. But what is it about the imp of English that is perverse, hence presumably helps to produce, as users of language, us imps? ${ }^{7}$ (CAVELL, 1994, p. 124).

Se o texto de Poe nos torna demônios, já que seus leitores, ou vice-versa, ou seja, se o gênio maligno das palavras se inscreve de maneira icônica sobre as páginas, vigiando-nos de soslaio e exigindo o alcance de nossa vigília, infere-se que no conto "The imp of the perverse" ocorre uma construção em duplo patamar (Dopelbodigkeit ${ }^{8}$ ) que deixa transparecer o drama vivido, na arte dramática da língua que o plasma. Ou seja, tal termo, derivado do teatro alemão, se refere ao palco com mais de um andar e, na terminologia filosófica, associa-se aos díssoì lógoi dos sofistas, discursos ambivalentes, que apontavam uma coisa, afirmando outra. Assim, ser encarcerado, emparedado pela linguagem de Edgar Allan Poe, não indicaria ser o ordinário uma questão filosófica da leitura? Ou ainda, não seria, segundo Cavell, tornar-se o leitor demônio, agenciador de um constructo semiótico, tal qual o narrador do relato, que, preso após a revelação do crime, se indaga: "Que me resta a dizer? Hoje suporto estas cadeias e estou aqui! Amanhã estarei livre de ferros! Mas onde?" (POE, 1981, 211).

\section{Referências bibliográficas:}

CAVELL, Stanley. Being odd, getting even (Descartes, Emerson, Poe). In: In the quest of ordinary: lines of skepticism and romanticism. Chicago: The University of Chicago Press, 1994.

\footnotetext{
${ }^{7} \mathrm{Na}$ minha tradução: “[...] se falar do demônio [imp] da perversidade é nomear o demônio em inglês, no que diz respeito aos sons iniciais de uma série de termos característicos de Poe, então falar de algo chamado perversidade que contém semelhante demônio é falar da linguagem mesma, em particular do inglês, como perversa. Mas o que há de perverso no demônio do inglês e que em consequência serve para nos fazer demônios, enquanto usuários da linguagem?"

8 A crítica literária alemã, reconhecendo-o como uma chave para o entendimento de autores excepcionais (Thomas Mann, Gehard Hautmann etc.), deu-lhe o emprego por mim adotado. Cf. Peter Delvaux (Antiker Mythos und Zeitgeschehen. Sinnstruktur und Zeitbezüge in Gerhart Hauptmanns Atriden-Tetralogie. Amsterdam/Atlanta: Editions Rodopi B.V., 1992) e Klaus Schröter (Thomas Mann im Urteil seiner Zeit. Hamburg: Rowohlt, 1969). Agradeço à Prof ${ }^{\text {a. }}$ Dr $^{\text {a. }}$ Carlinda Fragale Pate Nuñez a indicação referida.
} 


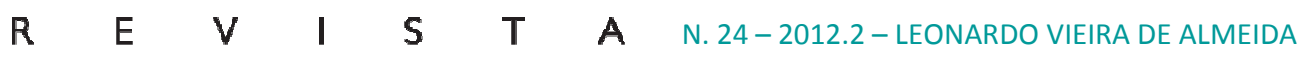

CHEVALIER, Jean; GHEERBRANT, Alain. Dicionário de símbolos: mitos, sonhos, costumes, gestos, formas figuras, cores, números. 9. ed. Rio de Janeiro: José Olympio, 1995.

DESCARTES, René. Meditações. In: Os pensadores: Descartes. São Paulo: Nova Cultural, 2000.

DELVAUX, Peter. Antiker Mythos und Zeitgeschehen. Sinnstruktur und Zeitbezüge in Gerhart Hauptmanns Atriden-Tetralogie. Amsterdam;Atlanta: Editions Rodopi B.V., 1992.

HAWTHORNE, Nathaniel. The scarlet letter. London: Penguin Popular Classics, 1994.

Wakefield. In: The works of Nathaniel Hawthorne. New York: Black's Readers Service Company, s/d.

Wakefield. http//:bestiário.com.br/5_arquivos/Wakefield.html. Acesso em 10/12/2012.

HOWARD, Leon. A literatura norte-americana. São Paulo: Cultrix, 1964.

MELLI, Filippo. Rembrandt. In: Coleção grandes mestres, v. 7. São Paulo: Abril, 2011.

POE, Edgar Allan. A balela do balão. In: Poesia e prosa. Rio de Janeiro: Edições de Ouro, 1966.

Contos de terror, de mistério e de morte. 7. ed. Rio de Janeiro: Nova Fronteira, 1981.

Resenhas de Edgar Allan Poe sobre Twice-told tales, de Nathaniel Hawthorne. In: A poética do conto. Porto Alegre: Nova Prova, 2004.

The imp of the perverse. In: Tales of mystery and imagination. London: Everyman's Library, 1946.

SABBATINI, Renato M. E. Frenologia: a história da localização cerebral. http://www.cerebromente.org.br/n01/frenolog/frenologia_port.htm. Acesso em 09/12/2012.

SCHRÖTER, Klaus. Thomas Mann im Urteil seiner Zeit. Hamburg: Rowohlt, 1969.

Towards a semiotics of evil: The imp of the perverse, by Edgar Allan Poe

Abstract: First published on the Graham's Lady's and Gentleman's Magazine in July 1845, the tale The imp of the perverse, by Edgar Allan Poe, deals with an uncommon incident: the deliberate murder through an act of reading. Trying to solve the secret reason of human impulsivity, Poe puts in question the acceptation of freedom, since man is free as far as thinking can lead to his perdition. In other words, if the first-person narrator breaks the law, searching for freedom, he achieves it in its own impossibility: he is free to lose the right to be 


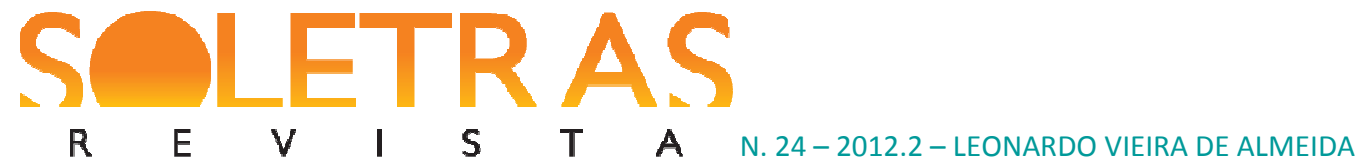

free. Thus, the paradox of Poe is composed by means of the proliferation of René Descartes' malignant genie described in his Meditations, who affirms itself by a semiotics of evil, a procedure that has in the anatomy of impulse its particular motive.

Key words: Semiotics of Evil. Parody. Meta-tale. Theory of the impulsivity.

Recebido em: 12 de dezembro de 2012.

Aprovado em: 29 de dezembro de 2012. 